$\frac{1}{2}$ c.cm. of the juice and liquor of the interior of each oyster was subjected to the special analysis.

2. The nearer to sewage outfalls, that is, the more exposed oysters and cockles are to sewage pollution, the greater the percentage of these shellfish polluted with B. coli communis.

3. The further away from sewage outfalls, or the smaller the amount of sewage accessible to the oysters or cockles, the smaller the number of these shellfish that are found to contain in the interior of their shells the B. coli communis.

\section{Method of Examination.}

The analysis of cockles and oysters for the purpose of detecting the presence of $B$. coli communis was carried out by me in the following manner: Of each bateh of cockles, 12 to 24 individuals were examined, and of each batch or sample of oysters, 10, 12, and sometimes 16 or 18 individuals. In all cases the shell of the fresh and living mollusc was thoroughly brushed with a clean brush under the running tap; then it was dried with clean cloth, opened with sterile instrument, and with the juice and liquor within the shell, cultures were established. Of each of six or eight oysters, about $\frac{1}{t}$ c.cm. ${ }^{6}$ of this liquor was added to one MacConkey tube and the same amount to one lactose tube; of further two, sometimes four, oysters, $\frac{1}{3}$ c.em. of this liquor was added to each of two, or in some cases four, phenol broth tubes, or in lieu (in the earlier analyses) about three big drops of the juice of each of two animals to establish two litmus glucose agar surface plates. : Next day, that is, after twenty-four hours' incubation at $37^{\circ} \mathrm{C}$., the necessary subcultures were made from the original tubes and plates in order to demonstrate the presence of $\mathrm{B}$. coli communis; streak and shake gelatine cultures, Mac(onkey and lactose peptone tubes, litmus milk, ordinary broth (with and without neutral red), litmus, lactose phenol agar plates, etc. From the turbid phenol broth also microscopic specimens stained by Gram method were made in order to detect the streptococci. Cultures on solid media may also be employed for their detection.

\section{Bacillus Enteritidis Sporogenes.}

Investigation of shellfish in the above sense has not been limited to the demonstration of $B$. coli communis. Examination has sought also the demonstration of the spores of $B$. enteritidis sporogenes. Spores of this bacillus are constantly present in domestic sewage to the number (as shown by Dr. Houston and myself) of from between 100 to 2,000 per I c.cm. These spores, as I have repeatedly shown, are present also in manure (consequentiy in street dust), and in all substances exposed to pollution with filth, manure, sewage, etc.

The presence, therefore, in shellifish of the spores of $B$. enteritidis sporogenes as well as $\mathrm{B}$. coli communis may serve as an additional indication of possibly recent sewage pollution ; at least, 'it is tolerably certain that oysters and cockles not Jaid down in sewage-polluted waters are free from the spores of this anaërobe, and also that the further away from definite sewage pollution the smaller the number of these shellfish which contain these spores.

Since the spores of $\mathrm{B}$. (enteritidis) sporogenes are, in sewage, greatly inferior in numbers to the B. coli communis, it is necessary to use a larger quantity $(0.5 \mathrm{c.cm}$.) of the shellfish material (juice and liquor) for each anaërobic milkculture tube if that anaërobe (B. enteritidis sporogenes) is to be demonstrated. Although, as I have repeatedly described, the milk culture may be typically changed by the twentyfour to thirty-six hours' growth of the above anaërobe, it does not follow that the so changed milk culture must be that of the B. (enteritidis) sporogenes; and in this connexion I cannot do better than illustrate by a reference to the already quoted papers by Professors Herdman and Boyce, that even experienced observers are liable to mistake some other andërobe for the B. (enteritidis) sporogenes. On p. 55 (loc. cit.) these observers state among their conclusions :

17. We have shown the frequent presence, in various shellfish, of anaërobic spore-bearing bacilli, showing the characteristics of the $B$ enteritidis sporogenes recently described by Klein

Now, examining the evidence on which this conclusion is based (see the table on p. 51), it is found that the authors have had before them the real virulent $B$. enteritidis sporogenes in cockle 1 , and possibly also in oyster 4 . But that in ull other shellfish examined by them (10 oysters, 6 mussels, 3 cockles, I periwinkle) the resulting growth was decidedly not that of B. enteritidis sporogenes (Klein), and for the sufficient reason that this latter microbe does not at any time $y$ In the case of cockles a lesser quantity is used, because there is not suficient in many of them to supply the required number of tubes. form spores in milk culture. The authors referred to, be it noted, describe the microbes cultivated by them in the milk cultures as either short or large spore-bearing bacilli.

It is quite clear, therefore, from Professors Herdman and Boyce's table that with the exception of 1 , or at most 2, shellfish out of the 22 bought by them indiscriminately in town shops, the shellish examined by them did not contain the B. (enteritidis) sporogenes. This is quite in agreement with what I find from $\mathrm{my}$ own recent investigations: out of 56 oysters analysed within a week, $x$ only contained the spores of this anaërobe. But out of other 8 oysters coming from a distinctly sewage-polluted laying, 4 contained these spores. Again, in a batch of 12 oysters coming from a laying in deep water far out from the shore. not a single one contained the microbe, whereas 4 out of ro in one batch, 5 out of 20 in another batch of oysters of the same locality, but laid comparatively near the sewer outfalls, contained the spores of B. (enteritidis) sporogenes, using always of each oyster $0.5 \mathrm{c.cm}$. for a culture tube.

It must, however, be obvious that the presence of the spores of B. (enteritidis) sporogenes alone-that is, without the simultaneous presence of $B$. coli communis-cannot be held sufficient proof that the oysters or cockles have been subjected to recent sewage pollution. For the spores of B. (enteritidis) sporogenes being, like other spores, highly resistant, may have found their way to the locality in which the shellfish had been kept any time (long or short) previous. But found together with $\mathrm{B}$. coli communis (and with streptococci) in oysters, the spores very probably had arrived in the locality recently, and in direct association with sewage and excremental matters.

\section{A NOTE ON BOSSI'S DILATOR IN ECLAMPSIA.}

\section{BY J. W. BALLANTYNE, M.D., F.R.C.P.E., F.R.S.EdiN.,}

Lecturer on Midwifery and Diseases of Women, Medical College for Women, Edinburgh: Examiner in Midwifery in the University of Edinburgh.

Tre management of cases of eclampsia in labour is still so unsatisfactory that obstetricians are glad to welcome and test any new plan of treatment which may seem to promise success. The rapid dilatation of the cervix uteri with Bossi's four-bladed dilator and the early termination of the labour by forceps or naturally is perhaps the newest method of management which has been placed before the profession. I have now dealt with three cases of albuminuria in pregnancy, two of which went on to eclampsia, by this method, and $I$ place the results on record in the hope that others who have experience in this direction may be induced to do so also.

I. My first case was that of a primipara, aged 23, who was admitted to the Edinburgh Royal. Maternity Hospital on the evening of November 13 th, 1902. She had had three convulsions before coming in, there had been marked vertex headache for two days previously, and the os uteri was about $r$ in. in diameter. The position was R. O.P. and the anterior fontanelle was felt presenting. She had a bad convulsion just after being brought into hospital. The pelvis was somewhat narrow, and there was a large amount of albumen in the urine (24 grams per litre). I inserted the Bossi dilator at Io p.m., and obtained full dilatation of the os in twenty minutes. I then applied forceps, but could not get rotation of the bead. There was evidence that the child was dead, so I performed basilysis and rapidly extracted. The child weighed $7 \mathrm{lb}$. without the brain and cranial vault bones. The mother made a slow but complete recovery. There was no laceration of the cervix. The diagonal conjugate was just over 4 in.

2. My second patient was a 4-para, 32 years of age, who was admitted to the Maternity Hospital on January 3rd, 1903, having been forty hours in strong labour in the first stage. She was given three successive hypodermic injections of morphine in the hope of suspending the uterine action and allowing the patient to get some sleep and rest, but after $1 \frac{1}{4} \mathrm{gr}$. had thus been given without any result, and as it was now discovered that there was albuminuria, I decided to dilate the cervix with the Bossi dilator. She had by this time been fifty hours in strong labour, and the os which was about 2 in. in diameter'had been of the same size for many hours. The presentation was the vertex, the position R.O.P. In half an hour, with the help of the-Bossi dilator, I completed the dilatation of the cervix, put on forceps, and delivered a living male infant weighing $7 \cdot 1 b .70 z$. Both the mother and child made good recoveries. 
3. I saw my third case in consultation with Dr. George Dickson, of'Ardmillan Terrace, Edinburgh, on February. Ioth. Dr. Dickson had not been engaged to attend this patient, a 1-para of about 24 years of age, but had been suddenly sent for as convulsions had supervened. She was six and a-half months advanced in pregnancy, and had had five fits in rapid succession before I saw her. There was much albumen in the urine, and the cervix was very rigid, the 08 being barely an inch in diameter. I dilated with the Bossi dilator in thirty-five minutes to a little over 3 in. diameter. As it was a premature labour I did not try to obtain full dilatation. In about half an hour afterwards the fetus was delivered with forceps; it was not viable. The mother has thus far (February 18th) made an uninterrupted recovery.

In none of these three cases had I any opportunity of dealing with the condition by prophylaxis, as all the patients werc in labour when I was summoned; in all of them morphine was

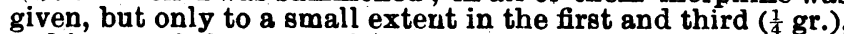
and in one of them (the first) the saline infusion was injected below both breasts.

I have dealt with many cases of eclampsia since I published my first cases in 1884 , and I think that if we accept the principle of early completion of labour as the treatment of the condition, then the Bossi dilator enables us to do this more quickly than any other means; further, it would seem to do so with safety if properly used.

\section{IS RUPTURE OF THE AORTIC VALVE AN ACCIDENT UNDER THE WORKMEN'S COMPENSATION ACT?}

Bx THEODORE FISHER, M. D., M.R.C.P.,

Patheiogist, Bristol Royal Infirmary ; Physician, "Out-Patients, to the Bristol Hospital for'sick Children.

In the British Medical Journal for January $3 \mathrm{rd}$, 1903 , is an annotation in which the question is raised whether rupture of the aortic valve can be considered an accident under the Workmen's Compensation Act. Probably few will deny that it appears possible that a healthy aortic valve segment may be ruptured under exceptional circumstances. For example, there seems to be some evidence to show that one or more coats of a healthy aorta may, in rare instances, rupture, and it must be supposed that an aortic valve segment has far less resisting power than the coats of a large artery; yet, although it may be admitted that a : healthy aorta may rupture, it is scarcely necessary to remark that the number of cases in which the vessel, wall gives way as the result of disease is immeasurably greater. But while this cannot be disputed and while it has long been known also that the aortic valve may be affected with the same disease or diseases as the aorta, yet the fact that, like the wall of the arterial trunk, a valve segment may yield and rupture as a consequence of such disease, appears to have been overlooked.

Difficult though it is to draw hard-and-fast lines between different forms of inflammation of the aorta, if there are not distinct diseases, at least there seem to be one or two varieties of disease. In one variety the formation of fibrous tissue is the leading feature, and in ancther the deposition of calcareons salts. The aortic valve may be affected by either of these varieties. There may be extensive deposit of calcareous salts or deformities of various kinds may be the result of fibroid thickening of the valve segments. Where fibroid changes are present in the aortic valve, and are associated with similar disease in the aorta, the disease has apparently spread from the aorta to the valve. In support of this view, it may be mentioned that a case may occasionally be seen where the disease of the aorta is limited to one sinus of Valsalva, and the valve segment below it alone of the three is affected. Usually the fibroid changes in the aortic valve result in diminution in size of the segments allowing regurgitation, and occasionally the regurgitation may be rendered more marked by the retroversion of one of them. At other times, however, a valve segment, when softened by inflammation spreading from the aorta, yields before the arterial blood pressure, and bulges towards the ventricle, as can be well seen in a specimen in the musenm of Guy's Hospital. In other cases a valve segment ruptures. In the Bristol Royal Infirmary Museum is a specimen (see illustration) showing an aortic valve segment which has ruptured, and above it the sinuses of Valsalva are affected with disease of the fibroid variety. Similar specimens may be seen in the Mugeum of the Royal College of Surgeons and of St. Bartho- lomew's Hospital, and another is figured in the work on $D_{i 3-}$ eases of the Heart, by Dr. Byrom Bramwell (p. 502). Perusal of records of cases of rupture of an aortic valve segment shows that the presence of disease of the aorta is invariably mentioned. Sir Walter Foster has recorded 3 cases in all of which the aorta was diseased $\left({ }^{1},{ }^{2}\right)$. The same is true of cases recorded by Frew, ${ }^{3}$ Orlebar, ${ }^{4}$ and Burney Yeo. ${ }^{5}$ One of the cases mentioned in Dr. Peacock's lectures is obviously the same as that from which the specimen in the Museum of the Royal College of Surgeons was obtained. It has already been inentioned that in that specimen the aorta is diseased. In the second case of Dr. Peacock the aorta is not mentioned, but the same case is recorded in the Medical Times and Gazette, 1859; vol. i, p. 171 ; and there patches of atheroma are said to have been present in the ascending aorta.

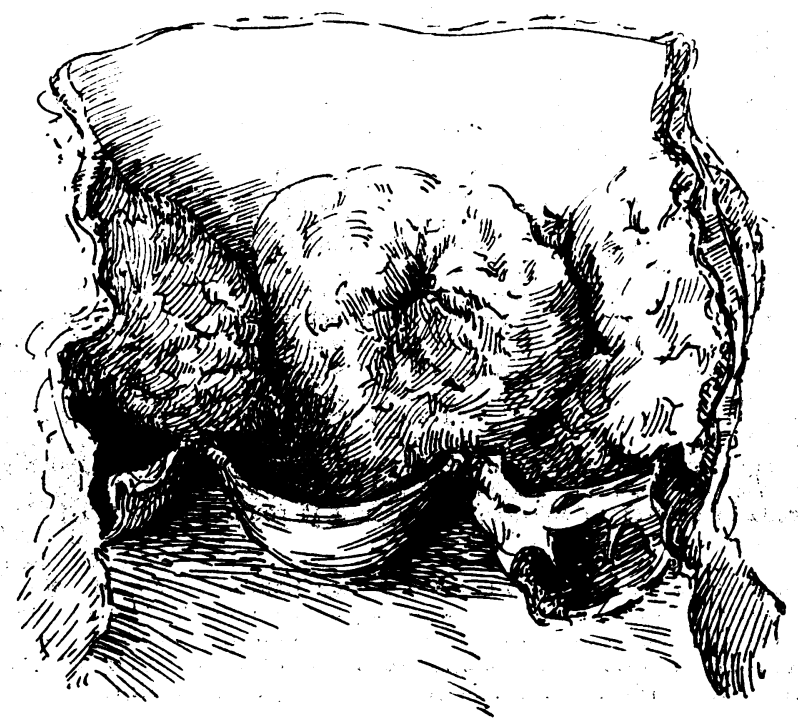

Rough sketch of a specimen showing ruptured aortic valve segment associated with disease of the aorta.

One other point of interest may be referred to. Whatever may be the cause of the disease or diseases of the aorta classified under the name atheroma, there can be little doabt that the more fibroid type occurs most commonly in men who have been abroad. Clinical notes do not always record all the more important details of a man's history ; but, judging not only from history, but from the characters of tattoo marks on the arms or elsewhere on the bodies of men who died of thoracic aneurysm and have come down to the post-mortem room of the Bristol Royal Infirmary, at least three out of four give evidence of having been soldiers or sailors, and have therefore presumably been in warmer climates. It is interesting to note in this connexion the previous history of the patients in those recorded cases of rupture of an aortic valve segment which have been referred to above. "In four out of the five cases in which the previous history is mentioned the men had been to the tropics. The disease of aorta and of the aortic valve may be the result of untreated syphilis, or possibly it may be the result of some infection of the blood vessels which is more common in warmer climates than with us; but, whatever the cause of the disease may be, the fact geems to me to be clear that rupture of an aortic valve segment is, in the majority of instances, a result of the same disease as that which produces aneurysm of the aorta.

\section{REFERENCES.}

1 Med. Times and Gazette, 1872, vol. ii, p. 657. 2 Path. Soc. Trans. vol. xvili, p. 49, 3 British Mrdical Journal, 1879, vol. i, p. 936, \& Path. Soc. Trans., vol. xxxi, p. 97. 5 Ibid., vol. $\mathrm{xxix,}$,. 63 .

\section{A NOTE ON THE THERAPEUTIC VALUE OF ADRENALIN.}

BY J. GRAY DUNCANSON, Woolwich.

THIs is claimed to be the active principle of the suprarenal gland, and is conveniently supplied in an aseptic solution as adrenalin chloride solution $\mathrm{I}$ in $\mathrm{I}, 000$, by Parke, Davis, and Co. 